\title{
Comunicación

\section{El lugar del columnismo político en el periodismo actual}

The place of political columnist in current journalism

ANTÓNIA DO CARMO BARRIGA ${ }^{1}$

Este ensayo discute el lugar que ocupa la "opinión" en el campo mediático, en el campo político, en el "mundo de los lectores" y en la jerarquía de las profesiones. Por otro lado, se propone caracterizar profesional y socialmente a los actores que firman las columnas de opinión, así como el modo como se construye su legitimidad. Por tanto, el presente ensayo pretende ser una contribución al marco conceptual de esta "actividad" y su argumento principal es que el lugar de los columnistas se comprende mejor cuando se piensa como un subcampo situado en la intersección entre el campo mediático y el político.

PALABRAS ClAVE: Columnistas, élites, campo, legitimidad.
This paper discusses the place the "opinion" fits in the media field, in political field, in the "world of readers" and in the hierarchy of professions. On the other hand, we intend to characterize both professionally and socially the actors who sign the opinion columns and how their legitimacy is built. This paper intends to be a contribution to a conceptual framework of this "activity" and its main argument is that the place of the columnists is best understood as a subfield at the crossroads of both the media and the political fields.

KEY WORDS: Columnists, elites, field, legitimacy.

1 Universidade da Beira Interior, Portugal.

Correo electrónico: acab@ubi.pt

Estrada do Sineiro s/n, C.P. 6200-209; Covilhã, Portugal. 


\section{LA IMPORTANCIA DE LA “OPINIÓN” EN EL ESPACIO MEDIÁTICO:} ALGUNAS APORTACIONES DESDE PORTUGAL

La presencia de columnas o textos de opinión en los periódicos no es actualmente una novedad, pero sí lo ha sido en las dos últimas décadas en el caso portugués. En un contexto de feroz competencia y concentración de la propiedad de los medios de comunicación, éstos, incluyendo la radio y la televisión, han incrementado de modo sistemático la presencia del comentario, el debate y el análisis de la actividad política.

Los cambios que hemos presenciado en las últimas décadas, en el ámbito de los medios de comunicación, y por extensión en la política, acompañan, coproducen y son en gran parte resultado de las transformaciones en el nivel económico, social y político de los países que las han sufrido. Así mismo, el incremento de los artículos de opinión en los medios y su creciente desarrollo hasta nuestros días acompaña los profundos cambios que se han operado en el mapa mediático y a la vez son su resultado, pues no han dejado de ser una contribución para las mismas.

La importancia de las columnas de opinión en el periodismo actual es claramente reconocible por su fuerte presencia en la mayoría de los periódicos. Incluso el valor que se da a la opinión -a la opinión de ciertos columnistas- es también evidente en las estrategias de promoción haciendo llamadas desde la primera página de la "cartera" de nuevos columnistas, o en las campañas publicitarias que los periódicos muestran, en las que la opinión promueve al periódico, apareciendo como un valor que le añade calidad. ${ }^{2}$

2 Véase a título de ejemplo, cómo el famoso periódico portugués Expresso, en enero de 2006 se publicitaba: "Más y mejor opinión en el Expresso", "opiniones que cuentan", o el anuncio publicitario, de noviembre de 2004 en el que el periódico Público utilizaba la metáfora "El 'Público" tiene columna". Esta estrategia de valorización y simultáneamente de autonomización del producto puede también observarse en la creación de títulos referenciales como "Espacio Público" u "Opinión". 
Pero la potenciación del papel de los columnistas se debe a varias razones, entre otras a las relacionadas con la innovación tecnológica y las estrategias empresariales. La innovación tecnológica ha contribuido a que la información se haya hecho continua, en directo, en "tiempo real", reduciendo el lapso de tiempo entre el momento en que las cosas ocurren y el momento en que pasan a ser divulgadas. Esto implica que el tiempo y el espacio que el periodista tenía para la interpretación y para el comentario se haya reducido considerablemente, lo cual ha allanado el camino para que otros ocupen ese papel (Rebelo, 2000).

Además, podemos admitir que "el registro" del comentario o del análisis es, por lo general, una manera de evitar el predominio del discurso de los actores políticos, considerado un "cassette" monocorde y "doctrinal" (Mesquita, 2003). También podemos entender el éxito de las columnas y crónicas de opinión por su capacidad de no limitarse, de forma distante, al relato de aquello que va sucediendo en la actualidad: nunca antes el individuo se había sentido rodeado por tantas noticias y nunca hasta ahora, dada su dispersión, había necesidad de reunir coherentemente y de dar sentido a esos hechos (Cantavela, 2004). En este sentido, diríamos, por analogía a la tesis de Luhmann (1995), que la función de las columnas de opinión sería reducir la complejidad de los propios medios de comunicación. Luhmann apoyándose en el concepto de sociedad de la complejidad, según el cual las transformaciones sociales y tecnológicas han aumentado las divergencias entre instituciones e individuos y entre los diferentes grupos sociales exacerbando la incertidumbre y la angustia, defiende que cabe a los medios proponer un conjunto de "temas orientadores" para la formación de la opinión, reduciendo con ello la complejidad social.

Cuando recurren a los columnistas los periódicos pretenden conseguir varios objetivos. Rebelo (2000) enumera algunos como: la creación de la ilusión de la pluralidad; la transferencia de responsabilidades fuera de su propia empresa; el desencadenamiento de juegos de espejos entre los medios y su público; la obtención de contrapartidas por los apoyos obtenidos de organizaciones políticas, culturales, religiosas, etcétera. 
Se admite, por ejemplo, que todo texto firmado supone un punto de vista que compromete en varios niveles, al periódico que lo publica. Las razones del periódico para incluirlo son diversas, puede hacerlo precisamente porque lo considera pertinente teniendo en cuenta su línea ideológica editorial (Moreno Espinosa, 2003); sin embargo, puede realizarlo justamente en contra de esa línea editorial, optando por dar voz a opiniones diferentes de la suya y dispares entre sí, recogiendo con ello dividendos de esa alusión (o "ilusión") a la pluralidad.

Así mismo, es a través de la "selección" de los columnistas, de la importancia que les dan o no, como los periódicos consolidan su política de opinión, definen su identidad y se afirman como sujetos semióticos en el sentido dado por Landowski (1989), esto es, como una entidad susceptible de ser reconocida por sus lectores, no solo como personalidad jurídica, sino también como resultado de su estilo, de su perfil. Como señala Joaquim Fidalgo (2000) "la elección de comentaristas, entre otros factores, ayuda a configurar la información global que llega a los receptores". Pero tal selección no deja de ser una estrategia comercial destinada a aumentar las audiencias.

Debido a las dificultades (crisis) a las que la prensa se viene enfrentando -entre las que destacamos solo las causas más visibles como el predominio del sector audiovisual, la información online o la creciente implantación de periódicos gratuitos- asistimos a una tendencia de reducción en la circulación y en las audiencias de los periódicos en papel, tendencia verificada en muchos países que conduce a que estos apuesten en otros "productos" que los valoricen.

No obstante, la opinión parece ser uno de esos productos/estrategias de valorización de los periódicos. Parafraseando a Resendes (2006), antiguo director del periódico portugués Diário de Notícias:

Un periódico de referencia basa, cada vez más, una parte significativa de su valor añadido en la cualificación, interés y pluralidad de sus columnistas ... Y la forma de transformar el coste de un periódico en una inversión para quien lo compra se encuentra menos en la divulgación de hechos que difícilmente suponen una novedad, que en la capacidad de contextualizar y profundizar esos hechos en el terreno de la opinión, preferentemente con la rúbrica del nombre de un comentarista creíble. 


\section{LA COLUMNA DE OPINIÓN: UN ESPACIO DE PODER}

Antes que nada, es necesario ver al periódico como un actor político, señalando que un actor político es todo actor individual o colectivo, susceptible de afectar al proceso de toma de decisiones en el sistema político; su ámbito de actuación no es la conquista del poder sino el de la influencia ejercida sobre el gobierno, los partidos políticos, grupos de interés, entre otros (Borrat, 1989). Evidentemente también es preciso señalar lo contrario, a saber: la influencia de los detentadores del poder político o de los grupos o empresas que los editan.

Pues bien, entre otros mecanismos y espacios informativos, el editorial y algunas columnas de opinión reflejan y representan extraordinariamente bien ese poder de influencia. Como señala Morán Torres (1988), aunque el editorial sea poco leído y por tanto no llegue a un público mayoritario, su influencia paradójicamente es muy poderosa. Diariamente y crecientemente se solidifica la opinión de aquellos para quienes "los lugares de mayor influencia política están en las columnas editoriales de los periódicos o en el posicionamiento de los telediarios" (Silva, 2003, p. 5).

Existen ejemplos, muy actuales, de cómo un artículo de periódico, a pesar del predominio de las nuevas tecnologías de la comunicación, ha perturbado gobiernos y conducido a la dimisión de ministros. Si bien es cierto que la cuestión de la influencia y de los efectos de las columnas de opinión es de difícil resolución, ésta no puede ser menospreciada. Aunque aquellos que leen periódicos y columnas de opinión sean un grupo minoritario, habrá que admitir "efectos indirectos" de distinta índole, ya sea sobre personas, temas o políticas.

Desde una perspectiva teórica marcada por el "determinismo estructural" (que se puede denominar como "estructuralismo constructivista") pero de incontestable y reconocida profundidad analítica, Bourdieu articula poder y lenguaje, en el marco de una pragmática sociológica que contextualiza, que indaga sobre lo que fundamenta la legitimidad o la validez de las acciones comunicativas e intercomprehensivas, que se centra en la legitimidad de quien habla.

Bourdieu (1989), denunciando "el error de Austin" (a pesar de que otros después de él también hayan persistido en este equívoco), se re- 
bela contra la búsqueda de "poder de las palabras en las palabras, o sea, en un lugar en el que éste no se encuentra" (p. 93). Bourdieu, al referirse a la constitución social de la "competencia lingüística" como una instancia de poder -el poder de "imponer la recepción", el derecho a la palabra, el lenguaje legítimo como lenguaje autorizado, como lenguaje de autoridad- evidencia esta dimensión de circulación del poder presente en el acto de la comunicación.

Todo acto de habla y, de un modo más general, toda acción, es una conjetura, un encuentro de series causales independientes: ... las disposiciones, del habitus lingüístico y ... las estructuras del mercado lingüístico, que se imponen como un sistema de sanciones y de censuras específicas (1989, p. 14).

Por lo que todo acto de enunciación posee una dimensión social y sociológica. "El uso del lenguaje ... depende de la posición social del locutor, la cual preside el acceso que éste puede tener al lenguaje de la institución, a la palabra oficial, ortodoxa y legítima" (Bourdieu, 1998, p. 97). Cuando alguien habla, habla desde un lugar, con una cierta autoridad. El discurso es pues, un instrumento de poder; poder de "clasificar", "ver" y "hacer ver" el mundo; poder que se manifiesta en las relaciones de fuerza establecidas entre los grupos que coexisten en la sociedad, donde cada cual opera con una competencia lingüística que le corresponde (Bourdieu, 1989).

Conviene por tanto subrayar, siguiendo a Bourdieu (1989), que la fuerza ilocutoria de ciertas expresiones no tienen su origen en la propia sustancia del lenguaje, sino fuera de él, el poder (de actuar sobre el mundo procediendo sobre la representación del mundo) se cumple sí, en y por la relación definida que produce/establece la creencia en la legitimidad de las palabras y de las personas que las pronuncian, y solo opera en la medida en que aquellas que lo soportan reconocen a aquellos que las ejercen; por consiguiente la eficacia de la palabra deberá pues relacionarse con la posición social del locutor. Es este el punto central de la cuestión sobre el discurso (de su poder, de su aceptabilidad, de su legitimidad) y también de los discursos de los columnistas. Sobre ella volveremos en el apartado final de este artículo. 


\section{COLUMNISMO: DE UNA SEMIPROFESIÓN A \\ UNA COMUNIDAD INTERPRETATIVA}

Este producto periodístico, el género llamado opinión, es frecuentemente calificado de no periodístico, puesto que mantiene fuertes vínculos con la actividad política a la vez que posee una indiscutible y sui generis relevancia social y capacidad de influencia. ¿Cómo conceptualizar entonces, sociológicamente, a estos actores y a esta actividad?

Hoy en día se puede decir del columnismo lo mismo que se decía del periodismo en un Diccionario de las Profesiones en la Francia de 1851:

El periodismo no es una profesión en el sentido habitual del término. Y esto es así en la medida en que recluta en las otras profesiones, habitualmente en las que exigen conocimientos generales, la abogacía, los profesores, los hombres de letras o de ciencias (citado en Traquina, 2004, p. 37). ${ }^{3}$

Sin embargo, utilizando la expresión de Pacheco Pereira (2005), él mismo también columnista, diríamos que existe hoy en día una industria del comentario, una industria de hablar/escribir bajo la forma de comentario, nacida al abrigo de las nuevas tecnologías, y que esta industria es una industria puntera.

Pero el conjunto de actores que firman las columnas de opinión o los editoriales en las páginas de los periódicos no constituyen un grupo especializado que posea el monopolio de conocimientos o de saberes particulares. A pesar de que el concepto de profesión continúe en construcción, máxime cuando en la sociedad moderna siguen emergiendo nuevas profesiones que aspiran al "estatus" de profesión, mientras que desaparecen otras que, aparentemente, ya se habían constituido como tales. Asistimos pues, en las sociedades contemporáneas a una intensa y dinámica reconfiguración profesional y social.

Los columnistas no son en rigor y desde el punto de vista formal, incluyendo el cuerpo de problematizaciones y conceptos de la sociología de las profesiones, considerados un grupo ocupacional.

3 El proceso de profesionalización del periodismo se aborda y encuadra teóricamente, por ejemplo, en Traquina (2004). 
Sin embargo, dado que parece asistirse en las sociedades actuales a un proceso de creciente profesionalización de la actividad de opinar, podemos sentir la tentación de considerarla como una cuasiprofesión o una semiprofesión, incluso cuando se rechace la idea de continuum, por referencia a un tipo idealmente definido que subyace en los primeros abordajes. Para ello es conveniente detenerse un poco en el concepto de profesionalización.

Pero para entender el poder de esta actividad conviene tener en cuenta las contribuciones hechas desde el enfoque del paradigma del poder (cuyos autores principales son Johnson, Freidson y Larson, a pesar de que muchos otros hayan hecho importantes aportaciones al mismo). Según este paradigma las explicaciones del fenómeno de las profesiones se amplían a criterios relacionados con el poder (profesional, económico, social y político de los propios grupos). Destacan los trabajos de Larson (1977), quien haciendo una síntesis de las tesis marxistas y weberianas estudia las profesiones como grupos de intereses (ligados al sistema de clases de la sociedad capitalista) y analiza la profesionalización como un proyecto de movilidad colectiva donde las ocupaciones aspiran a conseguir, además de posiciones económicas, un estatus social y prestigio. De este modo la profesionalización se entiende como un proceso de cierre social por el cual los grupos buscan maximizar sus resultados y sus recursos, limitando el acceso a un círculo restringido de candidatos. Estos procesos implican la exclusión, la oposición a otros grupos, y se justifican por el interés colectivo de servicio a la comunidad, teniendo así toda la legitimidad jurídica y apoyo político. $\mathrm{Y}$ es precisamente a un efecto de cierre social, a una especie de monopolio de competencias a lo que parece que asistimos cuando observamos los nombres de las primeras figuras que han venido expresando a lo largo de los años su opinión en los medios de comunicación.

Larsons, en 1988 (citada en Rodrigues, 1997) se sitúa en un cuadro teórico que también consideramos relevante para entender el poder del grupo que aquí nos ocupa (y que retomaremos más adelante). Defiende, inspirada en las tesis institucionalistas de Foucault, que el saber en sí no es suficiente para constituirse en un recurso, pues para demostrar la superioridad de un grupo será necesario desarrollar un proceso de 
construcción y apropiación de un discurso científico autorizado y autorizante. El éxito de ese proceso depende del contexto político y de la eficacia de los recursos (intelectuales, ideológicos, sociales) de los propios profesionales. Es interesante la utilización que la autora hace del concepto de Foucault de "campo de discurso" al abordar la relación entre el conocimiento científico y el poder de los profesionales, puesto que afirma que la profesión se ha convertido en:

Un medio casi omnipresente para construir la competencia, es decir de crear, organizar y presentar a los actores y a los espectadores la siguiente situación: he aquí una persona identificada por los signos particulares que pone a su disposición un saber superior al de otras personas que pueden perfectamente poseer más conocimientos y una excelente formación, pero en otros dominios (citada en Rodrigues, 1997 pp. 114-115).

De este modo se postula la existencia de un público lego que comprende las señales de competencia, es decir, comparte un marco cognitivo, facilitado no solo por el sistema educativo, sino también por el sistema mediático, en el cual se inscribe y acepta la superioridad de los especialistas.

Aunque no podemos considerar a los columnistas un grupo profesional, sí logramos identificar en ellos algunas características de tribu -expresión que Nelson Traquina (2004) utiliza para los periodistaso de comunidad interpretativa. Este concepto ha sido utilizado como parte de un enfoque alternativo a la comprensión de la diversidad de aspectos involucrados en las prácticas periodísticas que no son tomados en cuenta en el análisis del periodismo como profesión, ya que los rígidos criterios que definen la profesión no proporcionan un marco de referencia adecuado para la comprensión de la dimensión narrativa de la práctica periodística: el modo en que los periodistas crean una comunidad a través del discurso, las asociaciones y otros canales y formas de legitimación más allá de aquellas promovidas por su condición profesional. Esta forma alternativa de concebir la comunidad periodística ha sido conceptualizada en áreas más allá de los estudios de los medios de comunicación y el periodismo, sobre la base de la antropología, la etnología y los estudios literarios. 
Así, las "comunidades interpretativas", definidas como grupos unidos por su interpretación compartida de la realidad, según la definición de Hymes (citado en Zelizer, 2000), producen textos y "determinan la forma de lo que se lee" (Fish citado en Zelizer, 2000, p. 38), exhibiendo ciertos patrones de autoridad, de comunicación y de memoria cuando interactúan mutuamente (Degh citado en Zelizer, 2000), y estableciendo acuerdos tácitos y negociables que regulan la forma en que sus miembros pueden "reconocer, crear, sentir, y hablar sobre los textos" (Coyle \& Lindlof citados en Zelizer, 2000, p. 36).

En este sentido Zelizer (2000), entre otros, señala que "los periodistas están unidos, en tanto que comunidad interpretativa, por las interpretaciones colectivas de determinados acontecimientos clave" (p. 39). Tal como señala esta autora, la importancia de la creación de sentido a través del discurso es igualmente sugerida por la imagen que Park tenía de las noticias como una forma de conocimiento; por la definición de Carey de la comunicación como ritual y como cuadro común de comprensión; por las ideas de O'Brien sobre las noticias como un pseudomedio, y por los trabajos de Schudson sobre el modo como los periodistas construyen una imagen de sí mismos (Zelizer, 2000).

En el ejercicio de su actividad los periodistas comparten un marco de referencia, que Bourdieu (1997) identifica como estructuras cognitivas, perceptivas y valorativas, mediante las cuales la práctica periodística se basa en una serie de supuestos y creencias compartidas.

De manera similar a lo que algunos autores señalan, con referencia a la noticia, podemos preguntarnos; ¿en qué medida la opinión expresada refleja una cultura de grupo, un sistema de valores, un pensamiento de grupo susceptible de transformarse en un pack opinion (por similitud al concepto de pack journalism)?, ¿no es también la opinión un relato seleccionado de la realidad, una imagen refractada, consecuencia de un prisma (valores), en la terminología de Patterson (2000) o del uso de determinadas lentes, según Bourdieu (1997)?

Aparentemente, esto semeja una contradicción flagrante, pues habitualmente se califica a la opinión de libre, expresada en un registro eminentemente personal, presentándose muchas veces bajo la inocente forma de análisis. Se trata pues, de una creencia tan arraigada como lo fue, durante mucho tiempo, la de la objetividad periodística. 
Los datos disponibles corroboran la idea de que los columnistas funcionan en circuito cerrado, constituyendo grupos reducidos de lenta renovación, muchos de ellos presentes en la escena mediática desde larga data, y acumulando presencias en varios medios. Sin embargo, la idea de circuito cerrado, no se corresponde exactamente con la idea de que el discurso de los columnistas es una conversación exclusiva entre ellos, los propios periodistas, la élite política e intelectual y una minoría de la población.

\section{¿LA ÉLITE MEDIÁTICA:}

UN LUGAR DE RECLUTAMIENTO DE LOS COLUMNISTAS?

Parece evidente que quienes firman las columnas de opinión son una élite; aunque, dada la imprecisión del término, tal vez convenga realizar sobre este punto algunas consideraciones. Teniendo en cuenta la información empírica disponible, podríamos dividir a los columnistas que escriben sobre política en tres categorías: los que ejercen una actividad política/partidaria; los que ejercen una actividad cualificada (empresarial, técnica, académica, cultural), y los que tiene una presencia regular en los medios (en términos de tiempo/antigüedad y frecuencia/asiduidad) en función del valor de la opinión que emiten. Esta última categoría se subdivide a su vez en dos: los periodistas (directores, subdirectores, periodistas de prestigio), y otros actores que adquieren y refuerzan la visibilidad social y mediática a través de los espacios de opinión (estos últimos pueden tener vínculos con las categorías anteriores).

Estamos pues, en presencia de variables tan diferentes e imprecisas como la profesión, la posición que en ella se ocupa, la visibilidad mediática y social, el reconocimiento y el prestigio social (resultante de las variables anteriores, pero no totalmente explicado o legitimado por ellas), el ejercicio del poder, todo lo cual puede configurar, más que una clase social o un lugar de clase y sin perjuicio de otras categorizaciones, la existencia de una élite. Por lo tanto, entendemos que se trata de actores que pertenecen a las élites, partiendo de la definición genérica según la cual éstas comprenden "a las personas y a los grupos, que gracias al poder que detentan o a la influencia que ejercen, contribuyen para la acción histórica de una colectividad, ya sea por las decisiones 
tomadas, o bien por las ideas, sentimientos o emociones que expresan o simbolizan" (Rocher, 1971, p. 19).

Teniendo en cuenta las consideraciones de Higley y Burton (2003) se podría encuadrar a los columnistas en la élite política, dado que éstas "están formadas por aquellas personas que poseen la capacidad organizada de causar verdaderas perturbaciones políticas" (p. 280). Se trata de un elevado número de personas que "ocupan altos cargos en organizaciones y movimientos poderosos, debido a su tamaño o a cualquier otra razón, y que participan o influencian directamente los procesos de decisión política" (Higley \& Burton, 2003, p. 280). Así definidas, las élites políticas no solo incluyen a la élite del poder (de los líderes empresariales, gobernantes, jefes militares), sino también a todos aquellos que tienen cargos importantes, tanto en partidos políticos, asociaciones profesionales, grupos de interés de naturaleza diversa o medios de comunicación. Se supone que todos estos actores participan o influyen directamente en los procesos de decisión política, aunque algunos lo hagan a través del bloqueo u oposición a cualquier decisión (Higley \& Burton, 2003).

Pero también podemos definir la élite como el conjunto de individuos mejor cualificados en cada profesión que tienen cierta relevancia tanto sobre la población como entre sus colegas. En este sentido, cabe pensar que existe una élite entre los periodistas. La élite de los periodistas se refiere a una formulación más reciente, aún mal definida y que sociológicamente está poco estudiada, a pesar de que ya haya sido investigada empíricamente.

Algunos autores hablan indistintamente de élite periodística y de élite mediática, mientras que otros tienen concepciones diferentes sobre cada una de ellas, consideran que en la primera solo estarían incluidos los periodistas y que la segunda abarcaría otras categorías tales como políticos, artistas, empresarios, escritores, intelectuales, cuya característica común es su frecuente exposición o participación en los diferentes medios de comunicación (Santos-Sainz, 2003).

Sería pues, en esta categoría -la élite mediática- en la que estaríamos tentados de incluir a los columnistas. Sin embargo, la ausencia de conceptualización teórica de este concepto desaconseja su utilización. El criterio para incluir a alguien en esta élite plural, que a su vez está 
integrada por otras élites, es fundamentalmente la visibilidad que proyectan los medios de comunicación, especialmente la televisión (SantosSainz, 2003), lo que nos parece algo simplista e insuficiente. Nótese, por ejemplo, que Bourdieu (1998), solo se refiere al campo periodístico pero nunca utiliza los conceptos de élite periodística o mediática, incluso aunque haga referencia a ciertas categorías como la de las superestrellas mediáticas muy bien remuneradas o la de esos intelectuales periodistas, que se sirven de su doble pertenencia para eludir las exigencias específicas de ambos universos y para importar para cada uno de esos poderes mejor o peor adquiridos en el otro universo (Bourdieu, 1998). Del mismo modo, Champagne (1990) también evita su uso refiriéndose únicamente al campo mediático.

El estudio pionero de la élite periodística corresponde a Rieffell (1984, 1998) el cual analizó la composición, funcionamiento y prácticas de los dirigentes de la información en Francia. Para tal fin, entrevistó a 120 periodistas considerados como miembros de la élite en su campo: los que se encontraban en la parte superior de la jerarquía profesional (considera un criterio clave y que tiene una configuración amplia, donde se incluían redactores jefe o jefes de sección), pero teniendo también en cuenta indicadores como los altos salarios, su red de contactos, la audiencia/tirada de los medios en los que trabajaban, su reputación en el seno de la profesión, o el prestigio social obtenido por el poder.

María Santos-Sainz (2003) en la investigación empírica que llevó a cabo confirma la validez actual de estos criterios, pero subraya la creciente importancia de la visibilidad y la notoriedad otorgada por la televisión como criterio para definir la composición de la élite periodística. La televisión es una plataforma de lanzamiento y consagración, incluso para expresar la opinión en las tribunas de radio y de prensa.

Además, la visibilidad mediática se asume, para Bourdieu (1989), como una fuerza simbólica (antes ejercida por las sanciones internas): la consagración.

-Este nuevo principio de legitimidad- (y las concesiones a la lógica empresarial) concede a ciertos productos (culturales o incluso políticos) y a ciertos "productores" el sustituto aparentemente democrático de las sanciones específicas impuestas por los campos especializados (p. 88). 
De este modo, la consagración "reduce los derechos de entrada en incierto número de campos", pudiendo consagrar a personas que no pagaron esos derechos de entrada desde el punto de vista de la definición interna de la profesión (Bourdieu, 1989, p. 72).

Para identificar a la élite, Santos-Sainz (2003) empleó el método utilizado por los elitistas -método reputacional- que consiste en preguntar a los miembros de la élite periodística y a otros expertos quiénes en su opinión forman parte de la élite. Una vez contabilizadas las respuestas obtenidas en las entrevistas, la autora elabora un ranking de los primeros 10 periodistas franceses más citados. Metodológicamente (a pesar de que la autora cotejó este ranking con los nombres más citados en la bibliografía consultada y con la lista de periodistas que habían entrevistado al presidente de Francia, François Mitterrand y a Jacques Chirac, concluyendo que existía una gran similitud en su composición) nos parece cuestionable el criterio utilizado en la selección de los entrevistados -los lugares destacados que detentaban en la jerarquía de los medios de comunicación- resulta, en nuestra opinión, un tanto circular, pues establece de partida una distinción entre los que supuestamente van a sobresalir. Entendemos que esto solo se debería hacer si ya estuviesen definidos los valores internos de esa condición, la de la élite. Al igual que ocurre con los campos científicos en los que, como dice Bourdieu: "Un buen historiador es alguien de quien los buenos historiadores dicen que es un buen historiador" (citado en Santos-Sainz, 2003, p. 62) La cuestión de la composición de las élites, siendo importante (aunque seguramente no la única), nunca es una cuestión fácil.

\section{LA FORMACIÓN DE UN SUBCAMPO EN LOS MEDIA:}

UN LUGAR DE INTERSECCIÓN ENTRE EL CAMPO POLÍTICO Y EL CAMPO PERIODÍSTICO

Por tradición los columnistas son reclutados, principalmente, en dos campos: el de los media y el político -situándose en la convergencia de una vertiente mediática y de una vertiente político/partidaria, con valor político en cuanto sujetos mediáticos y con valor mediático en cuanto sujetos políticos (Rebelo, 2000)-. No obstante, existen actores provenientes de otros campos como el académico, todos ellos próxi- 
mos y en los que a menudo ocurren entrecruzamientos. Esta relación entre campos sucede por diversos motivos, bien porque se encuadra en las lógicas y reglas mediáticas; bien porque el columnista haya ejercido funciones políticas, o bien por encontrar en la temática "política" un dominio de reflexión e interés digno de ser explotado en el ámbito de los medios.

Es sabido que la tesis central de la teoría de los campos se fundamenta en el presupuesto de que las sociedades desarrolladas tienen como base una progresiva individualización y autonomía de los campos sociales, y que la formación de dichos campos sociales (con una estructura propia: valores, normas y papeles) se lleva a cabo en un marco genérico de organización y diferenciación de la actividad humana. El campo de los medios de comunicación - con funciones de mediación esencialmente simbólica- puede considerarse como una respuesta, en el nivel de la organización de la sociedad, al vasto conjunto de necesidades de orden cultural que surgieron de la generalización del lenguaje (Esteves, 1998). Pero en los campos sociales, estabilidad y cambio están siempre presentes y en permanente tensión, en ambos (político y mediático) convergen tanto la sociedad en su conjunto como cada uno de sus miembros (Esteves, 1998).

En el campo de los medios de comunicación, y en su relación con otros -el político es central- esas tensiones son notorias, ya sea por los condicionantes y elementos a las que están sujetas las funciones de la mediación social, ya por incorporar en su funcionamiento estrategias que nada tienen que ver con los procesos de mediación simbólica, ya porque suceda al margen de los medios, o bien por la proliferación de nuevas técnicas y dispositivos de información (Esteves, 1998).

Por lo tanto, en la senda de las afirmaciones de Adriano Duarte Rodrigues (1990) hay que aceptar que "el campo de los medios, al mismo tiempo que ve reforzado su papel en las sociedades desarrolladas, asume una forma más polifacética y polimorfa, que no autoriza, por consiguiente, su connotación estricta con los mass media" (Esteves, 1998).

Pero la acción discursiva de los columnistas -aunque usando explícita pero no exclusivamente los medios como vehículos, generando también algunas tensiones, reforzando simultáneamente algunas estra- 
tegias mediáticas y siendo ciertamente reveladora de alteraciones en el interior de los media-, ¿no configura especificidades suficientes para que podamos entenderla como una acción generada en un subcampo en reforzada relación con otros campos?

De este modo, y dada la especificidad que atribuimos a esta actividad de producción de opinión, y frente a la creciente aparente autonomía y legitimidad, conferida por el propio ámbito de los medios, casi individualizando y diferenciando ese bien propio que es la opinión transformada en pública - una especie de monopolio de competencias por parte de algunos-, nos parece posible entenderla como un producto de un subcampo del campo de los medios -lugar de intersección entre el campo político y el periodístico-, sometido a la coacción de este último (al igual que el campo político) y que sirve sobre todo a sus fines.

La emergencia de este subcampo contraria a la historia del periodismo en las democracias, es referida por Mark Deuze (2005) y descrita como el surgimiento de una identidad profesional de los periodistas con pretensiones de un rol y de un estatus exclusivo en la sociedad, ferozmente defendidos por su ideología ocupacional. Y va al encuentro al que el mismo autor denomina de periodismo líquido, una actividad con constantes desafíos y mutaciones.

Como es sabido, para Bourdieu (1989) la existencia de un campo, considerado como un "espacio social estructurado, un campo de fuerzas" (p.164) implica la existencia de un enjeu que se disputan agentes sociales diversos e implica la existencia de un grupo especializado que afirma poseer un monopolio de conocimientos o de saberes especializados. En el campo periodístico, el premio son las noticias y el grupo especializado los periodistas, los cuales detentan el monopolio de saber producir noticias. Ahora bien, la opinión, aunque firmada por periodistas, no remite para este premio ni deriva de estas competencias, sino que refiere para otro tipo de premios y competencias que el campo de los medios y su acción han autonomizado y legitimado progresivamente. Podríamos decir incluso que los textos de opinión hasta cuando están escritos por periodistas (aunque a veces sean indisociables de la materia noticiable que ayudan a interpretar) se aproximan más a los productos emanados del campo político que a los del periodístico (a pesar del movimiento inverso, esto es: la paulatina contaminación de los textos 
informativos por parte de la opinión). Tal aproximación puede explicarse en la medida en que se entiende el campo político como:

El lugar en que se genera, en la competencia entre los agentes que en él se hallan involucrados, productos políticos, problemas, programas, análisis, comentarios, conceptos, acontecimientos, entre los cuales los ciudadanos comunes, reducidos al papel de "consumidores", deben escoger con la probabilidad de malentendidos tanto mayores cuanto más alejados están del lugar de la producción (Bourdieu, 1989, p. 164).

Pero también hay otras similitudes y aproximaciones. El columnista, tal como el político (y tal vez más que el periodista, actor "anónimo") fundamenta su poder en la confianza y en la creencia, obtiene su fuerza de la confianza que un grupo deposita en él, da fe de la representación que él ofrece al grupo y de su relación con otros grupos (Bourdieu, 1989). En esa medida su poder, puesto que supone un reconocimiento -el desconocimiento de la violencia que se ejerce a través de él- es inmensamente simbólico. Su trabajo consiste en mejorar su credibilidad, su notoriedad. Tal como los políticos, los columnistas son portadores de un capital específico, simbólico, identificado por Bourdieu como un puro valor fiduciario, que depende de la fides, de la representación, de la opinión, del crédito y de la creencia.

Siguiendo a Bourdieu, podría decirse que los discursos políticos que los profesionales producen están siempre doblemente determinados, afectados por una duplicidad que resulta de la dualidad de los campos de referencia y de la necesidad de servir a los fines esotéricos de las luchas internas y, simultáneamente, a los fines esotéricos de las pugnas externas. La producción de la toma de posiciones depende del sistema competencial de tomas de decisiones propuestas por los partidos antagonistas. Por lo que los partidos, así como las tendencias que se generan en su seno, solo tienen una existencia relacional, su definición no es independiente de sus competidores. A nuestro entender, ésta es otra semejanza con el discurso de los columnistas.

Otra cuestión central, que interesa tratar aquí, es la de saber cuáles son los mecanismos mediante los cuales los columnistas adquieren la legitimidad para exponer sus opiniones en las páginas de los periódicos. 
Para ello comenzaremos por recurrir a Pedro Sorela (2000), quien no cree que sea posible conocer las múltiples causas por las que se contrata a un columnista (políticas, tribales, estéticas, económicas, sociales, etc.) ni lograr una clasificación de acuerdo con posibles criterios formales; esto no es posible porque los criterios difieren hasta el punto de no existir.

Pero, y siguiendo a Mario Mesquita (2004), hay que reconocer que la legitimidad del columnista se construye "en algún lugar en la intersección entre el derecho a la libertad de expresión y la libertad de creación de las empresas periodísticas", que supone "consensos mínimos entre diversas fuentes de decisión interna (dirección, redacción, a veces el criterio dominante entre los periodistas ...)" (p. 3). Se trata de una legitimidad frágil, basada en factores subjetivos y mutables. La contratación de los columnistas es, como refiere Michel Mathien (citado en Mesquita, 2004), una opción que se procesa en "la caja negra" de las empresas periodísticas.

De acuerdo con el filósofo portugués José Gil (2004), en "las estrellas opináticas" del espacio público, lo que influye y pesa como una plusvalía de sentido y de verdad en su discurso es la personalidad social de los interlocutores. Es una especie de argumento invisible para cuya fuerza contribuye su prestigio:

La condición de legitimación de un discurso es su paso por el plano del prestigio mediático -que, lejos de disolver el sujeto lo refuerza y lo enquista en una imagen "de carne y hueso", subjetivándolo como el mejor, el más competente, el que realmente merece estar el palco del mundo (Gil, 2004, p. 33).

En resumen, creemos que lo que autoriza y legitima a los columnistas para exponer sus impresiones o argumentos proviene, en gran parte, del poder simbólico - en el sentido que utiliza Bourdieu- que de partida ya detentan. Es un capital (científico, político, mediático) que se reconvierte o refuerza. Más que competencias comunicacionales, será este capital simbólico movilizado:

El poder que constituye el dato al enunciarlo, el poder de actuar sobre el mundo por medio de actuar sobre la representación del mundo, no reside en los "sistemas simbólicos", en forma de una fuerza "ilocutoria". Pero sí 
cumple en y por la relación definida que produce la creencia en la legitimidad de las palabras y de las personas que las pronuncian, y solo opera en la medida en que aquellas que lo soportan reconocen a aquellos que las ejercen (Bourdieu, 1989, p. 107).

Sin embargo, es necesario admitir que existen otros factores y otras perspectivas a considerar en el proceso de atribución de la legitimidad y credibilidad. Algunos autores preconizan la existencia de una relación de intimidad y confianza que se establece entre el columnista y sus lectores (López Pan, 1995b) y que origina el reconocimiento social.

De acuerdo con López Pan (2005), los columnistas al escoger los temas, las ideas, los estilos, al jerarquizar los valores, van revelando una personalidad, un modo de ser y de estar frente a los acontecimientos, ciertas preferencias morales -y a veces políticas-, determinadas intenciones y gustos. Son todos estos elementos lo que en la retórica clásica se llamaba ethos del orador. La coincidencia con ese ethos, ese cuadro de referencia individual, da lugar a una confianza originaria que dota al columnista de credibilidad y autoridad, en el sentido de reconocimiento social, y que se convierte en audiencia. No se trata tanto de una adecuación del columnista a los lectores, como de lo contrario: son los lectores los que encuentran en el periódico a alguien con quien están en sintonía y en quien confían, a los cuales se tornan fieles, en una atmósfera de intimidad. Según la perspectiva de este autor, es esa coincidencia habitual entre el columnista y el lector lo que hace que este último busque orientación, quiera una explicación que nazca de la confrontación entre lo que pasa en el mundo y los principios valorativos de alguien con quien coincide totalmente o en parte (López Pan, 1995a, 1995b, 2005).

Nos parece, no obstante, que para entender la relación entre los columnistas y sus lectores puede ser útil aludir al cuadro del contrato de lectura, conceptualizado por Verón (1985) -que va más allá del contrato enunciativo- referente también a la relación entre el soporte mediático y a su lectura, pero ampliado al tipo de relación que un determinado medio establece con su público y destinado a comprender los vínculos que establecen entre sí estas dos entidades del imaginario de la comunicación. 
Así, el éxito de un determinado medio se mide por su capacidad de proponer un contrato que articule correcta y eficazmente las expectativas, motivaciones, intereses y contenidos del imaginario de quien decide acceder a él; de hacer que ese contrato avance de forma que acompañe la evolución sociocultural de los lectores, preservando el nexo entre ellos, y también por su capacidad de modificar el contrato de lectura si la situación así lo exigiera, haciéndolo de un modo coherente (Verón, 1985). Además de los cambios socioculturales y de la situación de competencia es la dinámica de los lectores la que activa el contrato de lectura (y es de esta constante negociación con los lectores, de la aceptación de las estrategias de apropiación de las que dependen las propiedades del discurso del periódico).

En definitiva, el prestigio, la confianza que se atribuye a los columnistas (y a la relación que se mantiene con éstos), deriva y es deudora de la confianza que se tiene en el periódico (en función de varios criterios: el crédito en la veracidad de la información, pero también en sus visiones del mundo, su gusto, su estatus ...); es decir, la relación con los columnistas proviene igualmente del contrato ya establecido con el periódico (el mejor contrato hasta entonces, porque es el resultado de un favoritismo/preferencia por el periódico en un mercado competitivo).

Por otro lado, y porque en este contrato se negocia constantemente, tanto la apreciación que los lectores hacen con frecuencia de los columnistas, como sus decisiones (temas, modos de abordarlos ...) evidentemente intrincadas/relacionadas con las decisiones del periódico (elección de columnistas, paginación, titulares ...) pueden contribuir para mantener o romper el contrato (ruptura en la que es indudable que no están interesados los periódicos). Ésta nos parece, pues, una buena clave de lectura, capaz de ayudarnos a abrir y entender el lugar de los columnistas en el periodismo actual.

\section{UNA CUESTIÓN FINAL}

Teniendo en cuenta el lugar desde el que hablan: los columnistas, no es fácil conceptualizar la actividad que desarrollan. Para entender el lugar desde donde hablan reiteramos que sería pertinente situarlos en el subcampo de los medios de comunicación, en la intersección entre lo 
político y lo periodístico. Así, insistimos en subrayar que es necesario también entender al columnista como un portador de capital simbólico.

Pero, ¿cómo se reconocen ellos mismos identitariamente?, ¿qué es para ellos ser columnista?, ¿son aún periodistas, o ya sienten que forman parte de otra actividad distinta? Si así fuera, ¿cómo caracterizan dicha actividad?

Nos parece importante profundizar en futuros trabajos en la hipótesis de este subcampo, el hecho de que esta semiprofesión confiera identidad (profesional) a los columnistas. De ser así, esto solo será observable por el discurso, por las autopercepciones de los mismos, o por sus prácticas profesionales, a través de las interacciones entre sus iguales/pares, por las relaciones y vínculos que mantienen con los diversos media y con las otras estructuras organizacionales, abordados en una perspectiva más amplia y compleja.

\section{Bibliografía}

Barriga, A. C. (2007). Media, política e opinião: uma tríade complexa-

Uma abordagem à opinião publicada em Portugal. Tesis de doctorado. Iscte, Portugal.

Barriga, A. C. (2010). A emergência de um sub-campo: tentativa de conceptualização da actividade do colunista. Trajectos-Revista de Comunicação, Cultura e Educação, 16, 37-52.

Borrat, H. (1989). El periódico, actor político. Barcelona, España: Gustavo Gili.

Bourdieu, P. (1989). O Poder Simbólico. Lisboa, Portugal: Difel.

Bourdieu, P. (1997). Sobre Televisão. Oeiras, Portugal: Celta.

Bourdieu, P. (1998). Contrafogos. Oeiras, Portugal: Celta.

Cantavella, J. (2000). La columna informativa: un desafío de exigencia entre la omnipresente opinión. Estudios sobre el Mensaje Periodístico, 6, 53-62.

Cantavella, J. (2004). Redacción para periodistas. Informar e interpretar. Madrid, España: Ariel Editorial.

Champagne, P. (1990). Faire l'opinión. París, Francia: Minuit.

Charaudeau, P. (1983). Langage et discours: eléments de semiolinguistique. París, Francia: Hachette.

Deuze, M. (2005). What is journalism? Professional identity and ideo- 
logy of journalists reconsidered. Journalism, Theory Practice and Criticism, 5, 443-465.

Esteves, J. P. (1998). A ética da comunicação e os media modernos. Lisboa, Portugal: Edição Fundação Caloust Gulbenkian/Junta Nacional de Investigação Científica e Tecnológica.

Fidalgo, J. (5 de noviembre de 2000). As Linhas... e as Entrelinhas. Público. Recuperado el 28 de mayo de 2014 de http://static.publico. $\mathrm{pt} /$ nos/provedor/textos-fidalgo/prov20001105.html

Gil, J. (2004). Portugal hoje: o medo de existir. Lisboa, Portugal: Relógio d'Água.

Higley, J. \& Burton, M. (2003). Elites, classes politicas e democracia no seculo XXI. En A. C. Pinto \& A. Freire (Dirs.), Elites, sociedade, e mudanca politica (pp. 277-294). Oeiras, Portugal: Celta.

Landowski, E. (1989). Public opinion and its spokesmen. En P. Perron \& F. Collins (Eds.), Paris school semiotics (pp. 79-108). Amsterdam, Holanda/Filadelfia, PA, EE.UU.: Benjamins.

Larson, M. (1977). The rise of professionalism. A sociological analysis. Berkeley, CA, EE.UU.: University of California Press.

López Pan, F. (1995a). La columna como género periodístico. En F. López Pan (Ed.), 70 columnistas de la prensa española (pp. 11-32). Pamplona, España: Eunsa.

López Pan, F. (1995b). La columna periodística. Teoría y práctica. Madrid, España: Eunsa.

López Pan, F. (2005). El ethos retórico, un rasgo común a todas las modalidades del género columna. Ínsula. Revista de Letras y Ciencias Humanas, 703-704, 12-15.

Luhmann, N. (1995). Social systems. Stanford, CA, EE.UU.: Stanford University Press.

Mesquita, M. (24 de agosto de 2003). Palcos da discórdia. Público.

Mesquita, M. (25 de enero de 2004). As missas laicas da televisão. Público.

Morán Torres, E. (1988). Géneros del periodismo de opinión. Pamplona, España: Eunsa.

Moreno Espinosa, P. (2003). Géneros para la persuasión en prensa: los editoriales del diario El País. Ámbitos: Revista internacional de comunicación, 9-10, 226-238. 
Pacheco Pereira, J. (28 de febrero de 2005). Ar Puro [Mensaje de blog]. Recuperado el 22 de junio de 2006 de http://abrupto.blogspot. pt/2005/02/ar-puro-constable_28.html

Patterson, T. (2000). Doing well and doing good: How soft new critical journalism are shrinking the news audience and wakening democracy and what new oulets can do abaut it. Facultu Research Working Paper Series. Cambridge, MA, EE.UU.: Harvard University.

Rebelo, J. (2000). O discurso do jornal. Lisboa, Portugal: Editorial Noticias.

Resendes, M. B. (12 de enero de 2006). Senhor presidente, meu amigo. Diário de Notícias. Recuperado el 28 de mayo de 2014 de http:// www.dn.pt/Inicio/interior.aspx?content_id $=634908$

Rieffell, R. (1984). L'élite des journalistes. París, Francia: Presses Universitaires de France.

Rieffell, R. (1998). Analyse de l'élite des journalistes. Revue Française de Science Politique, 33(3), 428-454.

Rocher, G. (1971). Sociologia geral. Lisboa, Portugal: Editorial Presença.

Rodrigues, A. D. (1985). O público e o privado. Revista Comunicação e Linguagens, 2, 7-14.

Rodrigues, A. D. (1990). Estratégias da comunicação. Lisboa, Portugal: Presença.

Rodrigues, M. (1997). Sociologia das profissões. Oeiras, Portugal: Celta.

Santamaría Suárez, L. \& Casals Carro, M. J. (2000). La opinión periodística: argumentos y géneros para la persuasión. Madrid, España: Fragua.

Santos-Sainz, M. (2003). El poder de la élite periodística. Madrid, España: Fragua.

Silva, A. (8 de noviembre de 2003). O primeiro poder. Público.

Sorela, P. (2000). Las columnas impiden ver el bosque. Estudios sobre el Mensaje Periodístico, 6, 15-20.

Traquina, N. (2004). A tribo jornalística. Lisboa, Portugal: Editorial Notícias.

Verón, E. (1985). El análisis del "Contrato de Lectura", un nuevo método para los estudios de posicionamiento de los soportes de los media. Recuperado el 22 de junio de 2006 de http://www.catedras. 
fsoc.uba.ar/delcoto/textos/veron_eliseo_analisis_del_contrato_de_ lectura.pdf

Verón, E. (1988). Prensa escrita y teoría de los discursos sociales: producción, recepción, regulación. Langage, discours et societés, 4, 11-25.

Zelizer, B. (2000). Os jornalistas enquanto comunidade interpretativa. Revista Comunicação e Linguagens, 27, 33-61.

Fecha de recepción: 22/05/12. Aceptación: 26/08/12. 